$12-1992$

\title{
Laminar/Turbulent Oscillating Flow in Circular Pipes
}

Kyung H. Ahn

NASA Glenn Research Center

Mounir B. Ibrahim

Cleveland State University, m.ibrahim@csuohio.edu

Follow this and additional works at: https://engagedscholarship.csuohio.edu/enme_facpub

Part of the Mechanical Engineering Commons

How does access to this work benefit you? Let us know!

Publisher's Statement

NOTICE: this is the author's version of a work that was accepted for publication in International Journal of Heat and Fluid Flow. Changes resulting from the publishing process, such as peer review, editing, corrections, structural formatting, and other quality control mechanisms may not be reflected in this document. Changes may have been made to this work since it was submitted for publication. A definitive version was subsequently published in International Journal of Heat and Fluid Flow, 13, 4, December 1992, 10.1016/0142-727X(92)90004-S

\section{Original Citation}

Ahn, K. H., and Ibrahim, M. B., 1992, "Laminar/turbulent Oscillating Flow in Circular Pipes," International Journal of Heat and Fluid Flow, 13(4) pp. 340-346.

This Article is brought to you for free and open access by the Mechanical Engineering Department at EngagedScholarship@CSU. It has been accepted for inclusion in Mechanical Engineering Faculty Publications by an authorized administrator of EngagedScholarship@CSU. For more information, please contact library.es@csuohio.edu. 


\title{
Laminar/turbulent oscillating flow in circular pipes
}

\author{
Kyung H. Ahn* \\ Institute for Computational Mechanics in Propulsion, NASA Lewis Research Center, Cleveland, \\ $\mathrm{OH}, \mathrm{USA}$ \\ Mounir B. Ibrahim
Department of Mechanical Engineering, Cleveland State University, Cleveland, OH, USA
}

A two-dimensional oscillating flow analysis was conducted simulating the gas flow inside Stirling engine heat exchangers. Both laminar and turbulent oscillating pipe flow were investigated numerically for $R e_{\max }=1,920(\mathrm{Va}=80), 10,800 \quad(\mathrm{Va}=272), 19,300$ $(\mathrm{Va}=272)$, and $60,800(\mathrm{Va}=126)$. The results are here compared with experimental results of previous investigators. Predictions of the flow regime on present oscillating flow conditions are also checked by comparing velocity amplitudes and phase difference with those from laminar theory and quasi-steady profile. A high Reynolds number $k-\varepsilon$ turbulence model was used for turbulent oscillating pipe flow. Finally, the performance of the $k-\varepsilon$ model was evaluated to explore the applicability of quasi-steady turbulent models to unsteady oscillating flow analysis.

Keywords: unsteady flows; oscillating flows; turbulent modeling; computational fluid dynamics; critical Reynolds number

\section{Introduction}

The problems of periodic turbulent internal flow have been studied by many research workers experimentally as well as computationally (Hershey and Im 1968; Hino et al. 1983; Hino et al. 1976; Mizushina et al. 1975; Ohmi et al. 1982a, 1982b; Ramaprian and Tu 1983; Sarpkaya 1966). The periodic flow can be divided into two classes: (1) unsteady flow with nonzero mean velocity and (2) unsteady flow with zero mean velocity. Previous researchers have called the first class of periodic flow pulsating flow, and the second class oscillating flow.

The effect of imposed periodic pulsations on the timeaveraged properties has been previously investigated. Ramaprian and $\mathrm{Tu}$ (1983) found that for sufficiently high frequencies, the time-averaged flow variables, e.g., velocity, wall shear stresses, and power loss due to friction, were affected by the imposed unsteadiness. They also concluded that, from their computations, a quasi-steady turbulence model cannot adequately describe unsteady flow conditions, at least for high frequencies. Ohmi et al. (1982a) performed extensive pulsating flow experiments to determine transition criteria via nondimensional parameters on the basis of velocity measurements. The early investigations of Sarpkaya (1966), by detecting the growth rate of artificial disturbances, and of Hershey and Im

\footnotetext{
*Current address: Sverdrup Technology, Inc., 2001 Aerospace Parkway, Brook Park, OH 44142, USA.

Address reprint requests to Professor Ibrahim at the Department of Mechanical Engineering, Cleveland State University, Cleveland, $\mathrm{OH} 44115$, USA.
}

(1968), by friction factor measurements, show that critical Reynolds number $\operatorname{Re}_{\max , c}$ is much different from the steady-flow value of about 2,300 .

Hino et al. $(1983,1976)$ investigated oscillating turbulent flow in pipes and rectangular ducts experimentally for various Reynolds numbers and frequencies. Many useful turbulent-flow data have been generated through their work. They found that the turbulent energy production becomes exceedingly high in the decelerating phase, but the turbulence is reduced to a very low level at the end of the decelerating phase and in the accelerating stage of reversal flow.

So far, no extensive numerical calculations have been given for oscillating flows covering wide ranges of Reynolds number and frequencies. Köhler (1990) has performed numerical simulations of turbulent oscillating flows and compared mean velocity profiles and fluctuations with experimental results that were obtained from the oscillating-flow test facility at the University of Minnesota (see Seume and Simon 1986).

In this article, turbulent oscillating pipe flow has been analyzed by solving time-averaged continuity and momentum equations using the standard $k-\varepsilon$ turbulence model of Launder and Spalding (1974). A computer code, CAST, developed by Perić and Scheuerer (1989), has been modified to handle unsteady inlet conditions. Since most constants for this $k-\varepsilon$ model originated from steady turbulent flow measurements together with simplified assumptions, the validity of this quasi-steady turbulence model for unsteady flow conditions has been questioned. Performance evaluation of this $k-\varepsilon$ model for the present oscillating flow conditions will be discussed; one objective is to check the applicability of this quasi-steady turbulent model to oscillating flow analysis. 


\section{Analysis}

\section{Governing equations and numerical scheme}

The time-averaged equations of continuity and motion for an unsteady Newtonian fluid with constant fluid properties can be written as follows in vector form.

Equation of continuity:

$(\nabla \cdot V)=0$

Equation of motion:

$\rho \frac{D V}{D t}=-\nabla p-[\nabla \cdot \vec{\tau}]$

In handling turbulent flow conditions, the above dependent variables represent time-averaged values, and the turbulent shear stress term in Equation 2 is closed by the "high Reynolds number version" of the $k-\varepsilon$ turbulence model, which requires solutions of the following transport equations:

$\rho \frac{D k}{D t}=\nabla \cdot\left(\frac{\mu_{t}}{\sigma_{k}} \nabla k\right)+P-\rho \varepsilon$

$\rho \frac{D \varepsilon}{D t}=\nabla \cdot\left(\frac{\mu_{t}}{\sigma_{\varepsilon}} \nabla \varepsilon\right)+\frac{\varepsilon}{k}\left(c_{\varepsilon_{1}} P-c_{\varepsilon_{2}} \rho \varepsilon\right)$

The present $k-\varepsilon$ model has the eddy viscosity given by

$\mu_{t}=c_{\mu} \rho \frac{k^{2}}{\varepsilon}$

The production rate of turbulent kinetic energy is given by

$P=-\rho \overline{\left(u_{i}^{\prime} u_{j}^{\prime}\right)} \frac{\partial u_{i}}{\partial x_{j}}$

The empirical constants are the standard values: $c_{\mu}=0.09$, $c_{\varepsilon_{1}}=1.44, c_{\varepsilon_{2}}=1.92, \sigma_{k}=1.0, \sigma_{\varepsilon}=1.3$. The wall function method (Peric and Scheuerer 1989) is used to specify wall

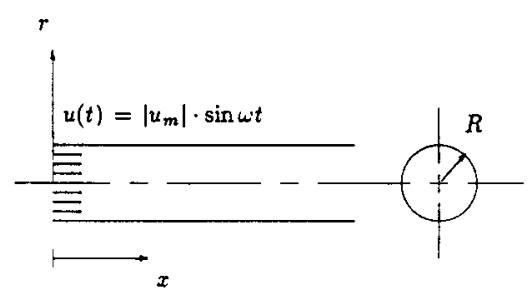

Figure 1 Geometry of the pipe and inlet condition for oscillating flow

boundary conditions. It should be observed that for the laminar flow regime, the flow undergoes flow reversal (near the wall), i.e., separation, during a small portion of the cycle. However, for the turbulent flow regimes, no such separation has been observed experimentally (Seume and Simon 1986). Accordingly, it appeared very plausible to use the classical wall functions for such an oscillating flow.

A conservative finite-volume method with collocated variable arrangement by Perić et al. (1989) is used for discretization. The convection fluxes in the model transport equations are discretized with the first-order upwind differencing scheme. Central differences are used to approximate the diffusion fluxes.

\section{Boundary and initial conditions}

Particular attention was paid to a flow geometry used by previous workers to perform the experimental oscillating flows (see Ohmi et al. 1982a). The flow geometry is a circular pipe, as shown in Figure 1, with diameter of $50.4 \mathrm{~mm}$ and length of $6,000 \mathrm{~mm}$; this gives $L / D \simeq 60$ at the middle section of the pipe. At this middle section, the flow can be considered fully developed. The inflow is taken to be uniform over the cross section and time dependent according to the relation

$u_{\mathrm{m}, \mathrm{in}}=\left|u_{\mathrm{m}}\right| \sin \omega t$

\author{
Notation \\ $c_{\mu} \quad$ Coefficient used in eddy-viscosity equation \\ $c_{\varepsilon i} \quad$ Turbulence model constants for $\varepsilon$ equation \\ $(i=1,2)$ \\ $D$ Diameter of the pipe, $\mathrm{m}$ \\ $k$ Turbulent kinetic energy, $\mathrm{m}^{2} / \mathrm{s}^{2}$ \\ $\left[=1 / 2\left(\overline{u^{\prime 2}}+\overline{v^{\prime 2}}+\overline{w^{\prime 2}}\right)\right]$ \\ $l \quad$ Turbulence length scale, $\mathrm{m}$ \\ $l_{\mathrm{m}} \quad$ Mixing length, $\mathrm{m}(=\kappa y)$ \\ $L \quad$ Length of the pipe, $\mathrm{m}$ \\ $p \quad$ Pressure, $\mathrm{N} / \mathrm{m}^{2}$ \\ $P \quad$ Production rate of turbulent kinetic energy, \\ $\mathrm{kg} / \mathrm{m} \mathrm{s}^{3}$ \\ $r \quad$ Radial coordinate, $\mathrm{m}$ \\ $R \quad$ Radius of the pipe, $m$ \\ $\operatorname{Re}_{\max }$ Reynolds number $\left(=\left|u_{\mathrm{m}}\right| \cdot D / v\right)$ \\ $t$ Time, $\mathrm{s}$ \\ $u \quad$ Axial velocity, $\mathrm{m} / \mathrm{s}$ \\ $|u| \quad$ Amplitude of axial velocity, $\mathrm{m} / \mathrm{s}$ \\ V Velocity vector, $\mathrm{m} / \mathrm{s}$ \\ $\mathrm{Va}$ Valensi number (dimensionless frequency) \\ $\left(=\omega \cdot R^{2} / v\right)$ \\ $x \quad$ Axial coordinate, $\mathrm{m}$
}

Greek symbols

$\delta \quad$ Stokes-layer thickness, $\mathrm{m} / \mathrm{rad}^{1 / 2}\left[=(2 v / \omega)^{\frac{1}{2}}\right]$

$\varepsilon \quad$ Dissipation rate of turbulent kinetic energy, $\mathrm{m}^{2} / \mathrm{s}^{3}$

$\lambda \quad$ Friction factor

$\eta \quad$ Dimensionless radial coordinate $(r / R)$

$\mu \quad$ Viscosity, $\mathrm{Ns} / \mathrm{m}^{2}$

$v_{f} \quad$ Kinematic viscosity, $\mathrm{m}^{2} / \mathrm{s}$

$\rho$ Density, $\mathrm{kg} / \mathrm{m}^{3}$

$\sigma_{k} \quad$ Turbulent Prandtl number for $k$ equation

$\sigma_{\varepsilon} \quad$ Turbulent Prandtl number for $\varepsilon$ equation

$\tau \quad$ Shear stress, $N / \mathrm{m}^{2}$

$\omega \quad$ Angular frequency, $\mathrm{rad} / \mathrm{s}$

Superscripts

Time-averaged value

Fluctuating velocity component

\section{Subscripts}

c Critical value

cl Values at a pipe centerline

$i, j \quad$ Denotes spatial coordinates $[=(r, x)]$

m Cross-sectional mean value

w Value at pipe wall 
Table 1 An outline of test cases

\begin{tabular}{|c|c|c|c|c|c|c|}
\hline Test case & $R e_{\max }$ & Va & $R e_{\max } /(V a)^{1 / 2}$ & Eq. 8 & $\begin{array}{c}\operatorname{Re}_{\max , c} /(\mathrm{Va})^{1 / 2} \\
\text { Eq. } 17\end{array}$ & Hino et al. (1976) \\
\hline $\begin{array}{l}\text { Case } 1 \\
\text { Case 2 } \\
\text { Case } 3 \\
\text { Case } 4\end{array}$ & $\begin{array}{r}1,920 \\
10,800 \\
19,300 \\
60,800\end{array}$ & $\begin{array}{r}80 \\
272 \\
272 \\
126\end{array}$ & $\begin{array}{r}215 \\
655 \\
1,171 \\
5,409\end{array}$ & $\begin{array}{l}882 \\
882 \\
882 \\
882\end{array}$ & $\begin{array}{l}620 \\
676 \\
676 \\
640\end{array}$ & $\begin{array}{l}770 \\
770 \\
770 \\
770\end{array}$ \\
\hline
\end{tabular}

\section{Flow computations and results}

Four cases have been studied for $2,000 \leqslant \operatorname{Re}_{\max } \leqslant 60,000$ with different oscillating frequencies (see Table 1). In the axial and radial directions, respectively, $62 \times 22$ grid nodes were used. A grid independence test has been carried out by doubling the grid nodes. For each case, 180 time steps were used in one cycle and the results were collected after four consecutive cycles. Convergence criteria have been set to 0.1 percent of the residual norms for every dependent variable at each time step, and about 2,000 seconds of CPU time (Cray XMP) per cycle has been used to achieve the convergence.

Ohmi and Iguchi (1982) derived the following critical Reynolds number for fully developed flow, up to which the theoretical correlation for laminar oscillating flow is valid:

$\frac{\mathrm{Re}_{\max , \mathrm{c}}}{\sqrt{\mathrm{Va}}}=882$

According to Equation 8, cases 1 and 2 are in the laminar regime and cases 3 and 4 fall into the turbulent regime (see Table 1). In the following sections, computational results for fully developed oscillating flow are analyzed for each test case by comparing with both experimental data (Ohmi et al. 1982a, 1982b) and steady-state analyses.

\section{Calculation of oscillating flow in the laminar regime}

Figures $2 \mathrm{a}$ and $2 \mathrm{~b}$ show the instantaneous velocity versus $\omega t$ at different radial locations for cases 1 and 2, respectively. The plots in those figures are made for the axial location at the
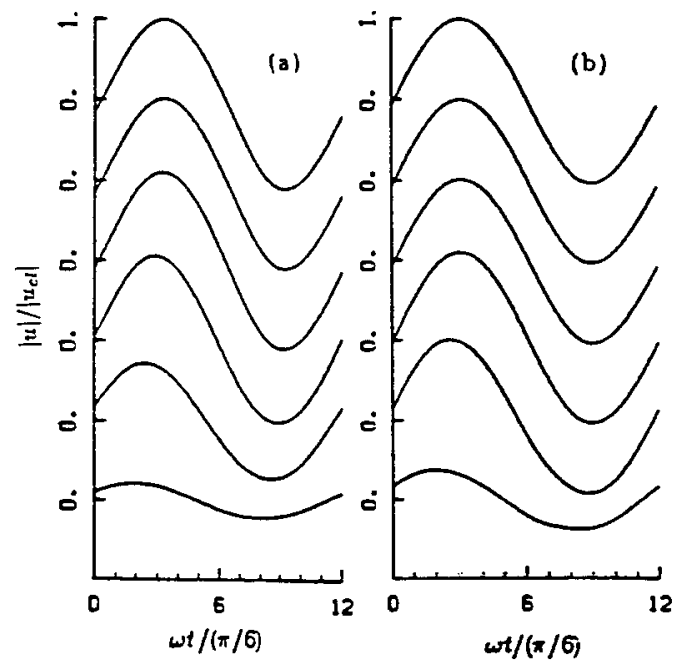

Figure 2 Laminar axial velocity distribution versus crank angle during a cycle: (a) Case 1 ; (b) Case 2. (Data were obtained at $r / R=0,0.25,0.55,0.75,0.88$, and 0.97 from top to bottom, respectively.) middle of the pipe. The plots show the increase in the velocity amplitude as the distance from the wall increases; also shown on the plot are differences in phase angle between the fluid motion near the wall and that near the pipe centerline. Profiles of the velocity amplitude normalized by the centerline value versus the normalized radial distance for cases 1 and 2 are shown in Figures 3a and 3b. Also shown on the plots are the phase differences between the velocity at any radial position and that of the centerline. In those figures, Ohmi's (1982b) experimental data for both amplitude ratio and phase differences are shown; an excellent agreement was obtained, except that near the pipe wall large discrepancies in phase differences are noticed. It was found from laminar theory that phase difference increases rapidly approaching the pipe wall, and the present numerical results follow the trend of laminar theory (Figures $3 \mathrm{a}$ and $3 \mathrm{~b}$ ). The same deviation between experimental and laminar theory was found in earlier work (Ohmi et al. 1982b). Consequently, the above discrepancies near the wall for phase differences can be attributed to difficulties in near-wall measurement. In Figure $3 b$, the dashed line represents the steady turbulent velocity profile ( $1 / 7$ power law). This shows that case 2 , although on the borderline between the laminar/turbulent regime, is very close to a laminar flow condition and still away from turbulent motion (see Figure 7).

\section{Calculation of oscillating flow in the turbulent regime}

Calculations were also made for oscillating flow in the turbulent regime. Inlet turbulent kinetic energy $k_{\text {in }}$ was obtained assuming isotropic turbulence (Köhler 1990):

$k_{\text {in }}=\frac{3}{2}\left(\mathrm{TI} \times u_{\mathrm{m}, \mathrm{in}}\right)^{2}$

where TI is turbulent intensity at the inlet, which is assumed to be 1 percent for cases 3 and 4 . Also, the turbulence length scale at the inlet $l_{\text {in }}$ was approximated by the following equation (Perić and Scheuerer 1989):

$l_{\text {in }}=\frac{k_{\text {in }}^{3 / 2}}{\varepsilon_{\text {in }}}$

Equation 10 holds under local equilibrium conditions and for a logarithmic velocity law (Rodi 1980). In the equation, the turbulent dissipation rate $\varepsilon_{\text {in }}$ was estimated from Equation 5:

$\varepsilon_{\mathrm{in}}=c_{\mu} \rho \frac{k_{\mathrm{in}}^{2}}{\mu_{t, \mathrm{in}}}$

The following assumption for turbulent viscosity (Köhler 1990) was used:

$\mu_{t, \text { in }}=\sqrt{\operatorname{Re}_{\max }} c_{\mu} \mu$

Then Equation 11, after substituting Equation 12, becomes

$\varepsilon_{\text {in }}=\frac{1}{\sqrt{\operatorname{Re}_{\max }}} \frac{k_{\text {in }}^{2}}{v}$ 


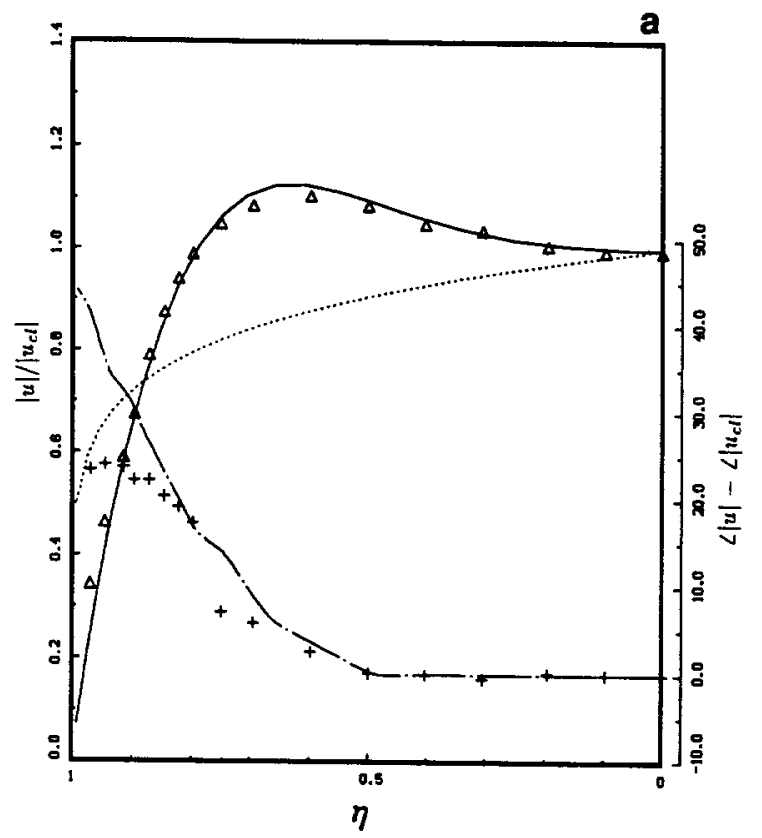

Figure 3a Profile of the velocity amplitude and phase difference for case 1. (Velocity amplitude-solid line: present numerical data; dashed line: $1 / 7$ power law profile; $\Delta \Delta \Delta$ : experimental data. Phase difference-chain dot line: present numerical data; +++ : experimental data.)

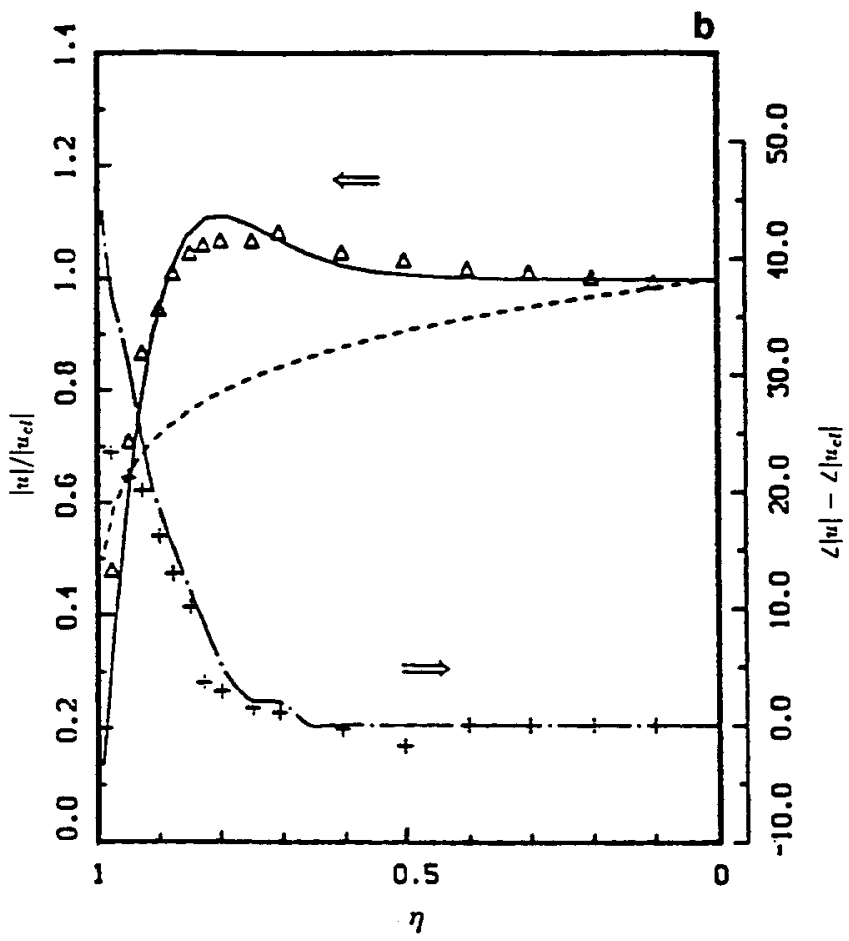

Figure $3 b$ Profile of the velocity amplitude and phase difference for case 2. (Velocity amplitude-solid line: present numerical data; dashed line: $1 / 7$ power law profile; $\Delta \Delta \Delta$ : experimental data. Phase difference-chain dot line: present numerical data; +++ : experimental data.)

With the above relationships, the turbulence length scale was estimated to be about 20 percent of the pipe diameter.

Computational results are shown in Figures 4 and 5 in the same order as in the laminar cases. Figures $4 a$ and $4 b$ show the time-averaged velocity versus $\omega t$ at different radial locations for cases 3 and 4, respectively. The plots show, in contrast with

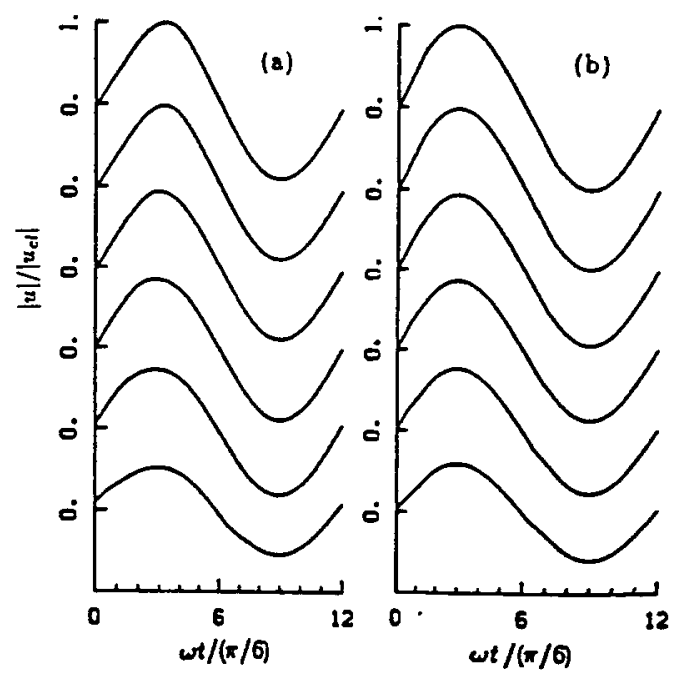

Figure 4 Turbulent axial velocity distribution versus crank angle during a cycle: (a) Case 3; (b) Case 4. (Data were obtained at $r / R=0,0.25,0.55,0.75,0.88$, and 0.97 from top to bottom respectively.)

the laminar cases, much less variation in velocity phase with radial position. Specially, in Figure $4 \mathrm{~b}$, no phase differences are shown across the pipe cross section. Profiles of the normalized velocity amplitude versus normalized radial distance for cases 3 and 4 are shown in Figures $5 a$ and $5 b$. Also shown on the plots are the phase differences between the velocity amplitudes. It should be noted that in case 4 the normalized velocity was obtained using the amplitude of the "cross-sectional mean" velocity (rather than that of the centerline, used in cases 1,2 , and 3). Also, the phase differences in case 4 were obtained from the difference between the velocity at any radial position and the "cross-sectional mean" velocity (rather than that of the centerline, used in cases 1,2 , and 3 ).

Experimental results for case 3 indicate that there are turbulent bursts in decelerating phase near the wall (Ohmi et al. 1982b). As seen in Figure 5a, numerical results for both velocity amplitude ratio and velocity phase differences are appreciably different from the experimental data, with maximum error of 14 percent and 40 percent, respectively. Also, in Figure 5a, two reference plots are shown for the normalized velocity, one for the laminar flow (dashed line) and the other for the $1 / 7$ power law profile (dotted line). It can be seen that the velocity amplitude ratio obtained numerically (solid line) nearly matches the 1/7 power law profile. Experimental data show intermediate values between the laminar and turbulent calculations in Figure 5a. This indicates that the flow regime for case 3 is in between laminar and turbulent (i.e., transient regime); therefore, the present high Reynolds number $k-\varepsilon$ turbulence model does not adequately predict the oscillating fluid motion in this regime.

In case 4, experimental results show turbulent bursts on the velocity distributions during most of the cycle and agree well with steady turbulent correlation (Ohmi et al. 1982a). In Figure 5b, numerical results also show good agreement with experimental data ( $<7$ percent). Specially, in Figures $4 \mathrm{~b}$ and $5 \mathrm{~b}$, both computation and data agree that the velocity phase remains nearly constant. Also, unsteady wall shear stress has been calculated and plotted in Figures $6 a$ and $6 b$ for cases 3 and 4, respectively. In each figure, the solid line represents present numerical results and the dashed line represents the results obtained from steady turbulent correlation. The wall shear stress has been normalized by a maximum steady-state 


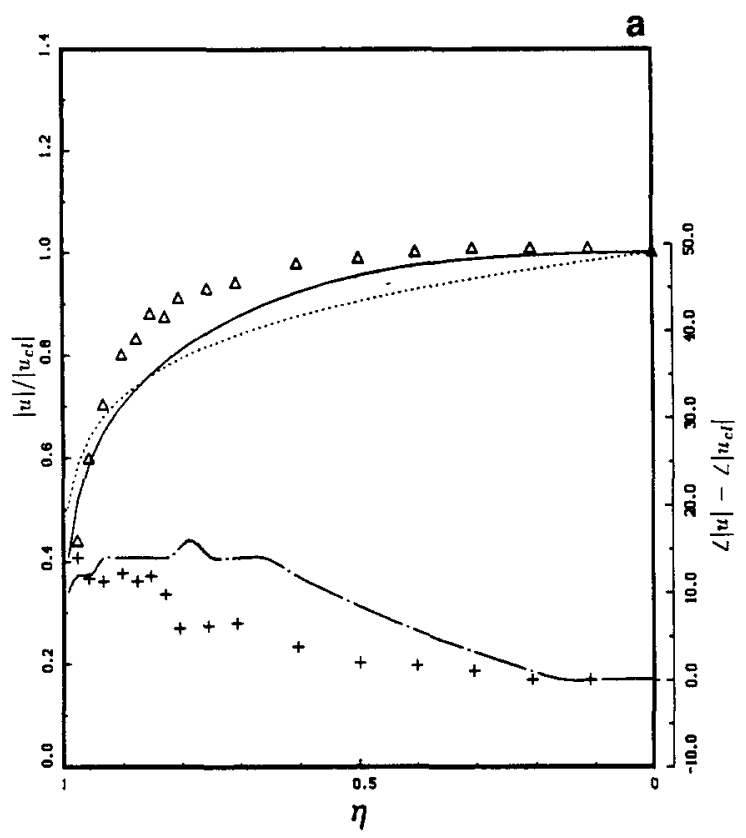

Figure $5 \mathrm{a}$ Profile of the velocity amplitude and phase difference for case 3. (Velocity amplitude-solid line: present numerical data; dashed line: laminar profile; dotted line: 1/7 power law profile; $\triangle \triangle \triangle$ : experimental data. Phase difference-chain dot line: present numerical data; +++ : experimental data.)

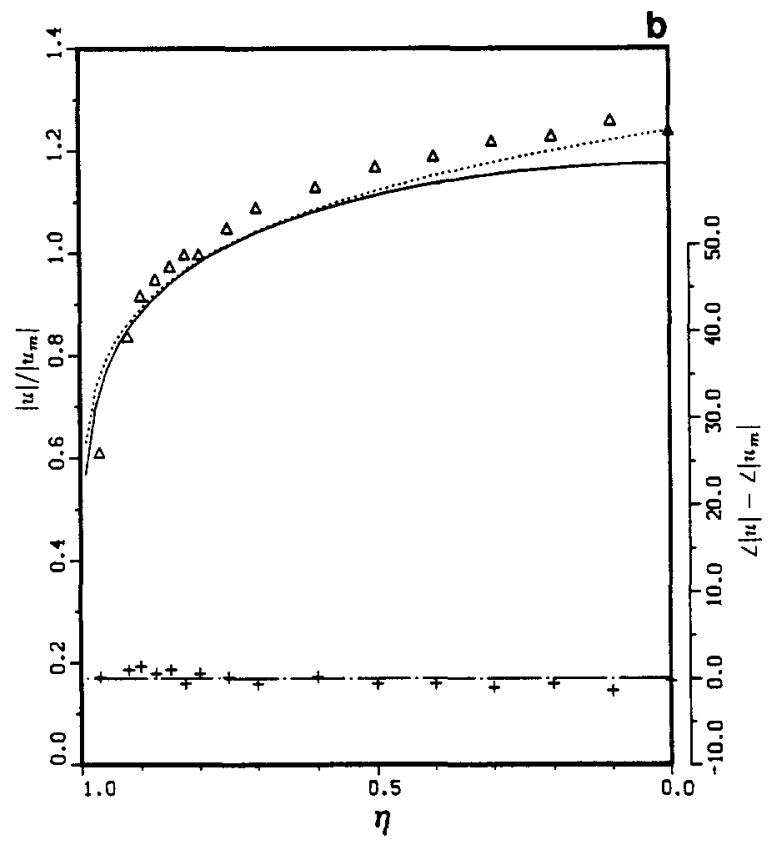

Figure $5 b$ Profile of the velocity amplitude and phase difference for case 4. (Velocity amplitude-solid line: present numerical data; dashed line: $1 / 7$ power law profile; $\Delta \Delta \triangle$ : experimental data. Phase difference - chain dot line: present numerical data; +++ : experimental data.)

value during a cycle and plotted versus $\omega t$ for a cycle. Like the earlier velocity results for cases 3 and 4 , the wall shear stress for case 3 deviates from a steady correlation, and for case 4 an excellent match has been obtained. Consequently, it is concluded that the flow regime for case 4 reaches the fully turbulent regime or turbulent quasi-steady state, as mentioned by earlier researchers.

\section{Critical Reynolds number}

Hino et al. (1976) summarized the critical Reynolds number from several experimental and theoretical results. From their work, two critical Reynolds numbers were found for the oscillating pipe flow. Experimental critical Reynolds numbers are found for $\operatorname{Re}_{\delta}$ based on the Stokes-layer thickness $\delta=(2 v / \omega)^{\frac{1}{2}}$ and the cross-sectional mean velocity amplitude $\left|u_{\mathrm{m}}\right|$, which can be expressed in terms of $\operatorname{Re}_{\max }$ and $\mathrm{Va}$ as in Equation 8:

$\frac{\operatorname{Re}_{\max , \mathrm{c}}}{\sqrt{\mathrm{Va}}}=\sqrt{2} \frac{\left|u_{\mathrm{m}}\right| \delta}{v}=\sqrt{2} \operatorname{Re}_{\delta, \mathrm{c}}$

Using visualization and power measurement techniques, Sergeev (1966) has determined the critical Reynolds number to be $\operatorname{Re}_{\delta, \mathrm{c}}=500$; using hot-wire measurement, Hino et al. (1976) obtained $\operatorname{Re}_{\delta, \mathrm{c}}=550$. These result in values for $\operatorname{Re}_{\max , \mathrm{c}} / \sqrt{\mathrm{Va}}$ equal to 710 and 770 , respectively. As mentioned earlier, Ohmi and Iguchi (1982) predicted a value of 882 (Equation 8 ). They also derived another expression for the critical Reynolds number using, instead of laminar oscillating flow theory, the following steady turbulent correlation together with the turbulence generation region assumption mentioned previously:

$\left.\begin{array}{l}\tau_{w}=\lambda \rho\left|u_{m}\right|^{2} / 8 \\ \lambda=0.3164 / \operatorname{Re}_{\max }^{1 / 4}\end{array}\right\}$

They obtained the following expression for the critical Reynolds number:

$\operatorname{Re}_{\max , \mathrm{c}}=(211 \sqrt{\mathrm{Va}})^{8 / 7}$

or

$\frac{\mathrm{Re}_{\max , \mathrm{c}}}{\sqrt{\mathrm{Va}}}=(211)^{8 / 7} \sqrt{\mathrm{Va}}^{1 / 7}$

in terms of the expression of Equation 14. The above critical Reynolds numbers are tabulated for each case in Table 1. Table 1 shows the flow conditions for each case examined in this article as well as the estimated values of $\operatorname{Re}_{\max , \mathrm{c}} / \sqrt{\mathrm{Va}}$ by different investigators.

Plotted in Figure 7 is $\sqrt{\mathrm{Va}}$ versus $\mathrm{Re}_{\max }$ showing the four cases examined in this study, as well as Equations 8 and 17 . From Figure 7, it is shown that case 1 is laminar and case 4 is turbulent according to available correlations (Equations 8 and 17). This finding is in agreement with the present numerical calculations. Case 2 is in the laminar flow regime according to Equation 8 and lies at the critical line (Equation 17); the present analysis shows that case 2 is laminar. Case 3 is in the turbulent flow regime according to Equations 8 and 17; however, the current analysis shows that it lies between laminar and turbulent. More extensive computations will be conducted to complete the map shown in Figure 7 from the computational point of view as well as from that of experimental data available today.

\section{Summary and conclusions}

Numerical calculations have been performed for oscillating flows in laminar, transition, and turbulent regimes, and comparisons with experimental data have been made. For turbulent computations, the Launder-Spalding $k-\varepsilon$ turbulence model has been employed with standard values of the model constants. The calculation method for the inlet values of turbulent kinetic energy $k$ and turbulent length scale $l$ has been 


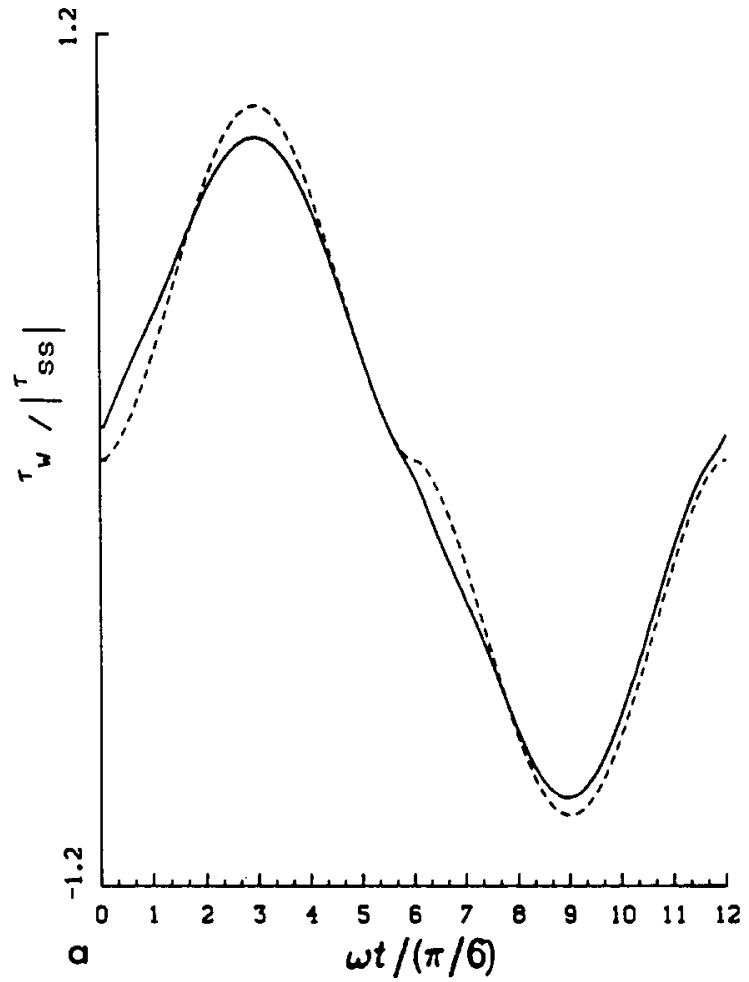

Figure 6a Normalized turbulent wall shear stress versus crank angle during a cycle for case 3. (Solid line: present numerical data; dashed line: turbulent steady correlation.)

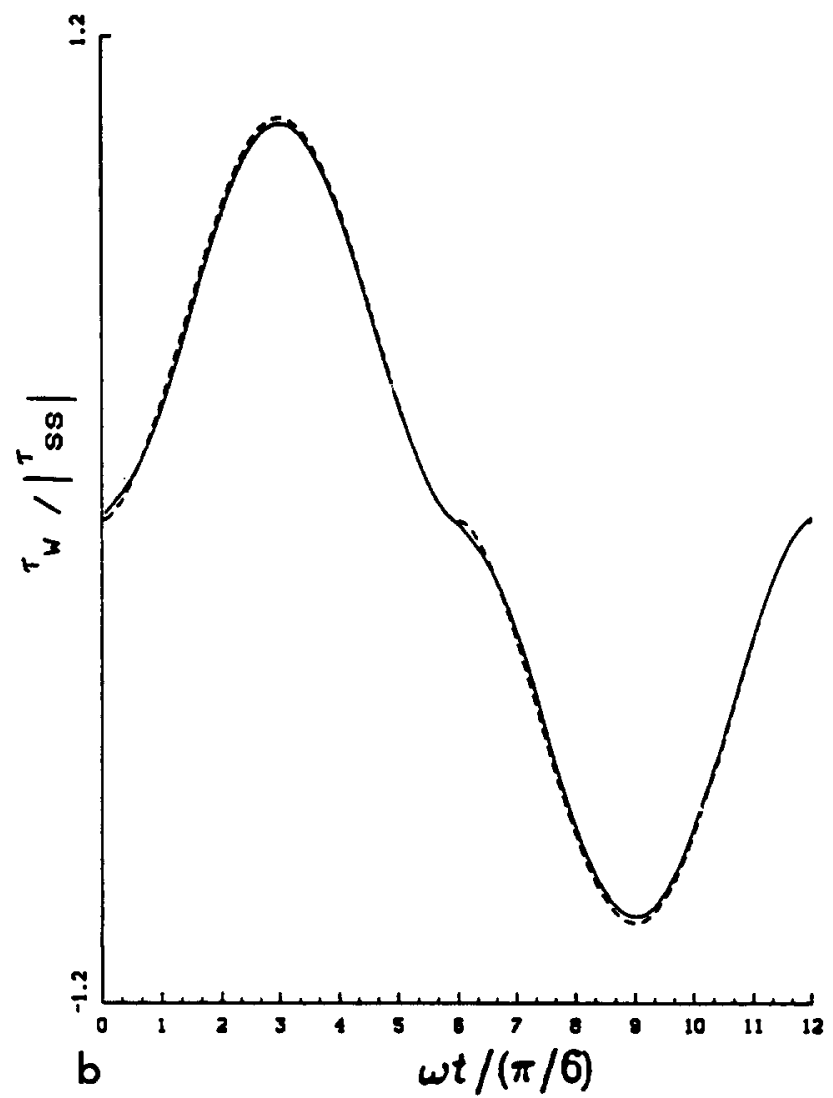

Figure $6 b$ Normalized turbulent wall shear stress versus crank angle during a cycle for case 4. (Solid line: present numerical data; dashed line: turbulent steady correlation.)

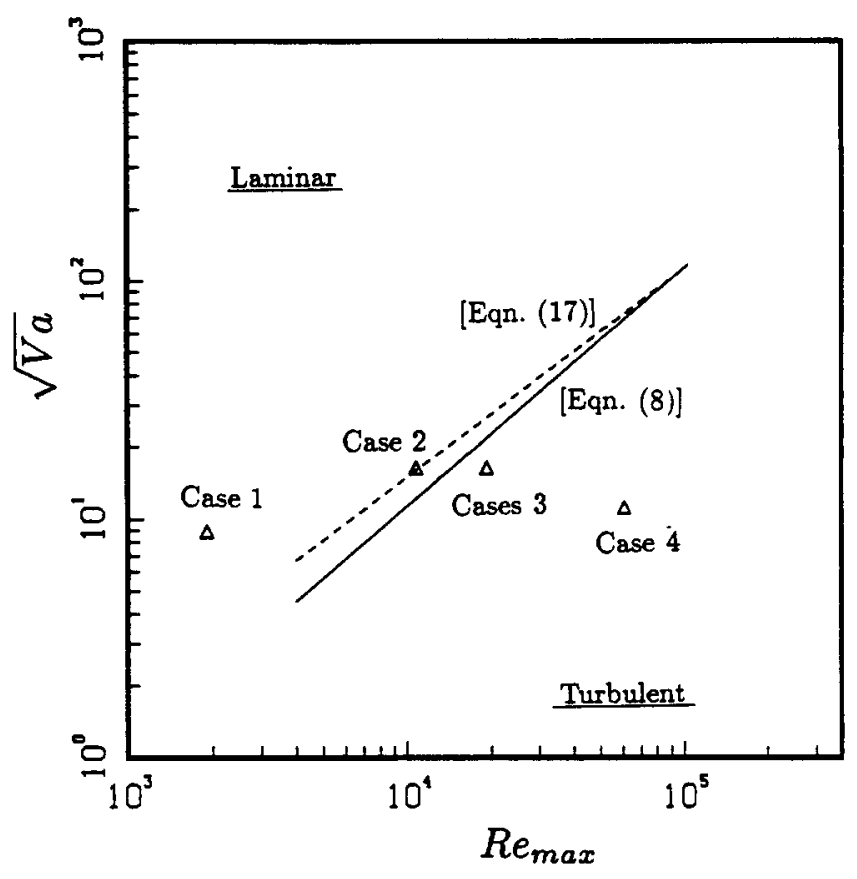

Figure 7 Oscillating flow regime and critical Reynolds number

discussed. Finally, several criteria for defining the critical Reynolds number for oscillating pipe flow have been reviewed and compared according to the present numerical results. The conclusions for the results of the present investigation are given below.

(1) Oscillating flow in a laminar flow regime can be simulated numerically with relatively high accuracy.

(2) The standard version of the $k-\varepsilon$ turbulence model cannot adequately model oscillating flow in a transition flow regime.

(3) For a fully turbulent regime or a quasi-steady turbulent regime, the standard version of $k-\varepsilon$ turbulence model can predict the oscillating flow within an allowable error.

(4) The critical Reynolds number defined by Ohmi et al. (1982a) from their experimental results seems to be reliable from numerical calculations. However, since the definition of a transition region is not clear and since the present numerical test data are scarce, extensive computations are needed to establish more reliable criteria for Stirling engine applications.

(5) For more rigorous numerical calculation for the oscillating flow in a transition regime, which is the case for most Stirling cycles, further improvement in turbulence modeling is also necessary.

\section{Acknowledgments}

The authors would like to express their thanks to Mr. Roy Tew of NASA Lewis Research Center for valuable discussions about this article.

\section{References}

Hershey, D. and Im, C. S. 1968. AIChE J., 14(5), 807

Hino, M., Kashiwayanagi, M., Nakayama, A., and Hara, T. 1983. Experiments on the turbulence statistics and the structure of a reciprocating oscillatory flow. J. Fluid Mech., 131, 363-400 
Hino, M., Sawamoto, M., and Takasu, S. 1976. Experiments on the transition to turbulence in an oscillatory pipe flow. J. Fluid Mech., 75, $193-207$

Köhler, W. J. 1990. Numerical prediction of turbulent oscillating flow and associated heat transfer. Ph.D. thesis, Dept. of Mechanical Engineering, University of Minnesota

Launder, B. E. and Spalding, D. B. 1974. The numerical computation of turbulent flows. Computer Methods Appl. Mech. Eng., 3, 269-289

Mizushina, T., Maruyama, T., and Hirasawa, H. 1975. Structure of turbulence in pulsating pipe flows. J. Chem. Eng. Jpn., 8, 210-216

Ohmi, M. and Iguchi, M. 1982. Critical Reynolds number in an oscillating pipe flow. Bull. JSME, 25(200), 165-172

Ohmi, M., Iguchi, M., and Urahata, I. 1982a. Transition to turbulence in a pulsatile pipe flow. Part 1, Wave forms and distribution of pulsatile velocities near transition region. Bull. JSME, 25(200), $182-189$

Ohmi, M., Iguchi, M., and Urahata, I. 1982b. Flow patterns and frictional losses in an oscillating pipe flow. Bull. JSME, 25(202), $536-543$
Perić, M., Rüger, M., and Scheuerer, G. 1989. A finite volume multigrid method for calculating turbulent flows. Proc. 7th Symp. on Turbulent Shear Flows, Paper 7-3, Stanford University, 7.3.1-7.3.6

Perić, M. and Scheuerer, G. 1989. CAST - A finite volume method for predicting two-dimensional flow and heat transfer phenomena. Gesellschaft für Reaktorsicherheit (GSR) Technical Notes SRR-89-01

Ramaprian, B. R. and Tu, S. W. 1983. Fully developed periodic turbulent pipe flow. Part 2, The detailed structure of the flow. J. Fluid Mech. 137, 59-81

Rodi, W. 1980. Turbulence models and their application in hydraulicsa state of the art review. Int. Assoc. Hydraulic Res., Delft, 115

Sarpkaya, T. 1966. Trans. ASME Ser. D, 88(3), 589

Sergeev, S. I. 1966. Fluid oscillations in pipes at moderate Reynolds numbers. Fluid Dynam., 1, 21-22

Seume, J. R. and Simon, T. W. 1986. Oscillating flow in Stirling engine heat exchangers. Proc. 2Ist Intersociety Energy Conversion Eng. Conf., San Diego, CA, IECEC Paper 869118, 533-538 